\title{
p53 and c-kit (CD117) protein expression as prognostic indicators in breast phyllodes tumors: a tissue microarray study
}

\author{
Puay-Hoon Tan ${ }^{1}$, Thiyagarajan Jayabaskar², George Yip ${ }^{3}$, Yen Tan ${ }^{1}$, Maryam Hilmy ${ }^{1}$, \\ Sathiyamoorthy Selvarajan ${ }^{1}$ and Boon-Huat Bay ${ }^{3}$ \\ ${ }^{1}$ Department of Pathology, Singapore General Hospital, Singapore; ${ }^{2}$ National Kidney Foundation, Singapore \\ and ${ }^{3}$ Department of Anatomy, Faculty of Medicine, National University of Singapore, Singapore
}

\begin{abstract}
Breast phyllodes tumors are fibroepithelial neoplasms whose clinical behavior is difficult to predict on histology. There is relatively scant data on the role of biological markers. In this study, we determined if p53 and CD117 (c-kit) protein expression was predictive of behavior in a series of $\mathbf{3 3 5}$ phyllodes tumors diagnosed at the Singapore General Hospital, using immunohistochemistry on tissue microarrays. Representative areas from $250(75 \%)$ benign, $54(16 \%)$ borderline and $31(9 \%)$ malignant phyllodes tumors were selected for construction of tissue microarrays using the $2 \mathrm{~mm}$ punch. Immunohistochemistry for p53 and CD117 was carried out using the streptavidin-biotin method. Staining proportion and intensity of both epithelial and stromal elements were analyzed. p53 immunostaining was observed in the epithelium of 28 (10\%) of 278 microarrays; myoepithelium of $53(21 \%)$ of 251 microarrays; and stromal cells in $105(36 \%)$ of 289 microarrays. CD117 immunohistochemical reactivity was noted in epithelial and stromal components of 175 (of 267, 66\%) and 17 (of $273,6 \%$ ) microarrays, respectively. Stromal p53 and CD117 protein expression was associated with tumor grade $(P<0.05) .0$ O $43(13 \%)$ women who suffered recurrences during the follow-up period, CD117 stromal staining predicted recurrent disease $(P<0.05)$, but p53 was not correlative. We conclude that tissue microarrays are a convenient method for evaluating immunostaining results of large numbers of phyllodes tumors. Although positive p53 stromal immunohistochemical detection may corroborate histologic malignancy, it is CD117 protein expression in phyllodes tumor stromal cells that may be of potential utility in predicting recurrent disease.
\end{abstract}

Modern Pathology (2005) 18, 1527-1534. doi:10.1038/modpathol.3800488; published online 16 September 2005

Keywords: grade; recurrence; biological markers

The clinical behavior of phyllodes tumors of the breast is difficult to determine. ${ }^{1-5}$ Histologic grade, ${ }^{6-8}$ stromal overgrowth, ${ }^{9,10}$ tumor necrosis and heterologous stromal elements, ${ }^{11}$ as well as a combination of morphologic parameters, ${ }^{12}$ have been traditionally used as predictors of clinical outcome. Nevertheless, specific parameters that can independently define recurrent likelihood are not universally agreed upon. $^{2}$ A substantial number of reports have concluded that it is the adequacy of surgical margins that is most important, ${ }^{5,6,12-14}$ and that histologic features have an inconsistent predictive role.

We recently described the pathologic parameters of a large series of phyllodes tumors, ${ }^{15}$ and found

Correspondence: Dr P-H Tan, MD, Department of Pathology, Singapore General Hospital, Outram Road, 169608 Singapore. E-mail: gpttph@sgh.com.sg

Received 5 May 2005; revised 28 July 2005; accepted 1 August 2005; published online 16 September 2005 that grade, as well as the individual histologic components of stromal atypia, stromal hypercellularity and permeative microscopic borders were correlated with recurrent disease. On multivariate analysis however, it was margin status, as well as pseudoangiomatous stromal hyperplasia that were independently predictive of recurrence.

Beyond morphology, investigators have studied the role of biological markers in phyllodes tumors, with p53 perhaps being the most widely evaluated. ${ }^{1,16-19}$ p53 expression has been described as being associated with malignant histological features, but does not appear to predict recurrent likelihood. ${ }^{1,17}$ Recently, $C$-kit (CD117) expression was also observed in malignant phyllodes tumors, although its impact on recurrence was not addressed. ${ }^{20,21}$

In this study, we employed p53 and CD117 immunohistochemistry on our previously described phyllodes tumors using the tissue microarray technique, and correlate the results with histological parameters and clinical outcome. 


\section{Materials and methods}

\section{Patients and Tumors}

These cases of breast phyllodes tumors were diagnosed between January 1992 and December 2002 at the Department of Pathology, Singapore General Hospital. Patient details and tumor laterality were determined from accession forms, while tumor size was obtained from the surgical pathology reports. Histologic review and classification into benign, borderline and malignant categories, as previously defined, ${ }^{15}$ relied on a constellation of findings, namely degree of stromal hypercellularity, cytologic atypia, mitotic activity, stromal overgrowth and nature of the borders (circumscribed vs permeative).

Patient follow-up was obtained from casenotes and the Singapore Cancer Registry, National Disease Registries Office.

\section{Tissue Microarray Construction}

The arrays were constructed with the $2 \mathrm{~mm}$ punch on the Beecher arrayer. ${ }^{22}$ The array layout in grid format was designed using Microsoft Excel. Hematoxylin and eosin (H\&E)-stained sections of phyllodes tumors were reviewed and the area of interest marked out on the slide. Using a marker pen, the corresponding region was circled on the archival 'donor' paraffin block. The samples were then arrayed on to a 'recipient' blank block. The $2 \mathrm{~mm}$ punch was selected as it allowed easy manipulation during punching; with the larger individual sample size offering more lesional tissue for assessment. Difficulties encountered in the construction of tissue microarrays were overcome as earlier described. ${ }^{22}$

A total of 59 phyllodes tumors were subjected to more than one punch per case: 52 cases with two microarray cores; four cases with three microarray cores; and three cases with more than three microarray cores (two with four cores and one with six cores) each.

\section{Immunohistochemistry}

Immunohistochemical staining was assessed in both epithelial and stromal components. The proportion of cells stained, as well as the intensity of staining, was evaluated. For staining intensity, 0, 1+, $2+$ and $3+$ defined nil, weak, moderate and strong reactivity, respectively. p53 staining was assessed in the cell nuclei, while CD117 was evaluated in the cytoplasm and cytoplasmic membrane. Any unequivocal staining, regardless of intensity and proportion of cells stained, was regarded as positive. For cases with more than one microarray constructed per case, staining was scored separately and the results compared. The finding that yielded the highest scores was used in the analysis. The degree of agreement of stromal immunostaining in these cases was ascertained.

Sections $(4 \mu \mathrm{m})$ were cut from the tissue microarray blocks and fished onto coated slides (POLYSINE, Menzel-glaser) in a similar orientation to facilitate faster evaluation. The slides were then baked in the oven overnight at $55^{\circ} \mathrm{C}$ to enhance adhesion of the sections to the slides. Deparaffinization in xylene and through graded alcohol followed. For the p53 antibody, sections were subjected to pressurized superheating in Milestone T/T Mega for $4 \mathrm{~min}$ at $120^{\circ} \mathrm{C}$ in $0.01 \mathrm{M}$ citrate buffer, then cooled for 4 min under running water, then stained with the p53 antibody (D07, Dako M7001, 1:70 dilution) using the Envision ChemMate Kit on the Dako Autostainer. For CD117, sections underwent pressurized superheating in Milestone T/T Mega, for $4 \mathrm{~min}$ at $115^{\circ} \mathrm{C}$, in Dako S3307 pH9 buffer and then were cooled for $4 \mathrm{~min}$ under running water. The sections were then stained with the CD117 antibody (c-kit, Dako A4502, 1:250 dilution) using the Envision ChemMate Kit on the Dako Autostainer. After that, the sections were counterstained with hematoxylin, dehydrated and mounted in depex.

A breast carcinoma known to be positive for p53, and a CD117 positive case of gastrointestinal stromal tumor, were used as positive controls; with mast cells also serving as an internal positive for CD117. Negative controls were accomplished by omitting the primary antibody with each batch run.

\section{Statistical Analysis}

Statistical analysis was carried out using the software SPSS for windows release 11.5. Patient age, histologic parameters and recurrences were correlated with p53 and CD117 immunostaining results using the $\chi^{2}$ test. The Mann-Whitney $U$-test was used to compare means between variables. A $P$-value of $<0.05$ was considered a significant result.

\section{Results}

\section{Patients and Tumors}

A total of 335 women were diagnosed with phyllodes tumors during the study period, with ages ranging from 16 to 69 years (mean 41 years, median 42 years). Details are as previously documented. ${ }^{15}$ Briefly, tumor size for the series ranged from 0.9 to $25 \mathrm{~cm}$ (mean $5.4 \mathrm{~cm}$, median $4 \mathrm{~cm}$ ). Histologic classification revealed 250 (75\%) benign, 54 (16\%) borderline and 31 (9\%) malignant lesions. Other morphologic parameters are shown in Tables 1 and 2 .

\section{Tissue Microarrays and Immunohistochemistry}

Of 335 cases of phyllodes tumors, the maximum number of microarrays that could be scored was 289 . 
Table 1 Clinicopathologic features of phyllodes tumors correlated against p53 stromal immunostaining

\begin{tabular}{lccc}
\hline $\begin{array}{l}\text { Clinicopathologic } \\
\text { feature }\end{array}$ & $\begin{array}{c}\text { Negative p53 } \\
\text { stromal staining }\end{array}$ & $\begin{array}{c}\text { Positive p53 } \\
\text { stromal staining }\end{array}$ & P-value \\
\hline $\begin{array}{l}\text { Grade/classification } \\
\text { Benign }\end{array}$ & 150 & 69 & \\
$\quad$ Borderline & 24 & 20 & 0.004 \\
Malignant & 10 & 16 & \\
Stromal hypercellularity & & & \\
Mild & 110 & 42 & \\
Moderate & 60 & 48 & 0.004 \\
$\quad$ Severe & 14 & 15 & \\
Stromal overgrowth & & & \\
Absent & 171 & 84 & 0.002 \\
Present & 13 & 21 & \\
Epithelial metaplasia & & & \\
Absent & 181 & 98 & \\
Present & 3 & 7 & $<0.040$ \\
P53 immunostaining of epithelium & & \\
$\quad$ Negative & 172 & 76 & \\
Positive & 7 & 21 & \\
P53 immunostaining of myoepithelium & & \\
Negative & 164 & 36 & \\
Positive & 16 & 37 & \\
\hline
\end{tabular}

In some cases, the microarray cores were incomplete, with donor cores that were too thin or not able to sit snugly within the recipient blocks, resulting in either loss of tissue or incomplete sections when cutting.

Results of immunohistochemical staining of p53 and CD117 on the tissue microarrays are detailed in Tables 3 and 4, respectively.

For 59 cases that were subjected to duplicate, triplicate and more microarray cores, $50(85 \%)$ and $54(92 \%)$ revealed agreement of p53 and CD117 immunohistochemical findings, respectively, when positive vs negative stromal staining was compared.

\section{p53}

The number of microarrays suitable for evaluation of p53 immunohistochemical staining on epithelial, myoepithelial and stromal components was 278, 251 and 289, respectively. The quantum of luminal epithelium available for analysis in each microarray was variable, sometimes demonstrating only a short stretch; and because myoepithelial cells were not always discerned in tandem with luminal epithelium, the number of microarrays in which myoepithelial staining could be documented was fewer. Table 3 shows the distribution of p53 immunohistochemical results, including staining intensities, in histologically benign, borderline and malignant phyllodes tumors. The proportion of epithelial cells decorated with p53 ranged from 1 to $10 \%$ (mean $4 \%$,
Table 2 Clinicopathologic features of phyllodes tumors correlated against CD117 stromal immunostaining

\begin{tabular}{|c|c|c|c|}
\hline $\begin{array}{l}\text { Clinicopathologic } \\
\text { feature }\end{array}$ & $\begin{array}{l}\text { Negative CD117 } \\
\text { stromal staining }\end{array}$ & $\begin{array}{l}\text { Positive CD117 } \\
\text { stromal staining }\end{array}$ & $\mathrm{P}$-value \\
\hline $\begin{array}{l}\text { Age (mean, in years) } \\
\text { Grade/ } \\
\text { classification }\end{array}$ & 40.8 & 47.0 & 0.029 \\
\hline Benign & 199 & 7 & \\
\hline Borderline & 37 & 4 & $<0.001$ \\
\hline Malignant & 20 & 6 & \\
\hline $\begin{array}{l}\text { Tumor size (mean, } \\
\text { in } \mathrm{mm} \text { ) }\end{array}$ & 49.6 & 85.9 & $<0.001$ \\
\hline \multicolumn{4}{|l|}{ Gross margins } \\
\hline $\begin{array}{l}\text { Well } \\
\text { circumscribed }\end{array}$ & 216 & 11 & 0.009 \\
\hline $\begin{array}{l}\text { Poorly } \\
\text { circumscribed }\end{array}$ & 11 & 4 & \\
\hline \multicolumn{4}{|l|}{ Gross necrosis } \\
\hline Absent & 250 & 13 & \\
\hline Present & 6 & 3 & $<0.001$ \\
\hline Not mentioned & 0 & 1 & \\
\hline \multicolumn{4}{|l|}{ Gross hemorrhage } \\
\hline Absent & 229 & 12 & \\
\hline Present & 27 & 4 & $<0.001$ \\
\hline Not mentioned & 0 & 1 & \\
\hline \multicolumn{4}{|l|}{ Stromal atypia } \\
\hline Mild & 190 & 7 & \\
\hline Moderate & 51 & 7 & 0.010 \\
\hline Marked & 15 & 3 & \\
\hline \multicolumn{4}{|l|}{ Microscopic borders } \\
\hline $\begin{array}{l}\text { Pushing/ } \\
\text { circumscribed }\end{array}$ & 180 & 7 & 0.015 \\
\hline Permeative & 76 & 10 & \\
\hline \multicolumn{4}{|c|}{ Stromal hypercellularity } \\
\hline Mild & 135 & 4 & \\
\hline Moderate & 99 & 6 & $<0.001$ \\
\hline Severe & 22 & 7 & \\
\hline \multicolumn{4}{|l|}{ Stromal overgrowth } \\
\hline Absent & 228 & 10 & 0.002 \\
\hline Present & 28 & 7 & \\
\hline \multicolumn{4}{|l|}{ Stromal metaplasia } \\
\hline Absent & 248 & 14 & 0.024 \\
\hline Present & 8 & 3 & \\
\hline \multicolumn{4}{|l|}{ Myxoid change } \\
\hline Absent & 28 & 5 & 0.040 \\
\hline Present & 228 & 12 & \\
\hline \multicolumn{4}{|l|}{ Infarction or necrosis } \\
\hline $\begin{array}{l}\text { No infarction or } \\
\text { necrosis }\end{array}$ & 198 & 10 & \\
\hline Infarction & 53 & 3 & $<0.001$ \\
\hline Tumor necrosis & 5 & 4 & \\
\hline \multicolumn{4}{|c|}{ P53 stromal immunostaining } \\
\hline Negative & 167 & 4 & 0.002 \\
\hline Positive & 88 & 12 & \\
\hline
\end{tabular}

median 5\%) (Figure 1a). Myoepithelial cell staining ranged from 1 to $30 \%$ (mean $7 \%$, median $5 \%$ ), while stromal cells stained from 1 to $80 \%$ (mean $15 \%$, 
Table 3 Association of p53 immunostaining with grade of phyllodes tumors

\begin{tabular}{|c|c|c|c|c|c|}
\hline p53 immunohistochemistry & Benign no. & Borderline no. & Malignant no. & Total no. & $\mathrm{P}$-value \\
\hline \multicolumn{6}{|l|}{ Epithelium } \\
\hline Negative & 195 & 37 & 18 & 250 & 0.32 \\
\hline Positive & 20 & 7 & 1 & 28 & \\
\hline $1+$ & 8 & 4 & 1 & 13 & 0.405 \\
\hline $2+$ & 12 & 3 & $\boldsymbol{O}$ & 15 & \\
\hline Total & 215 & 44 & 19 & 278 & \\
\hline \multicolumn{6}{|l|}{ Myoepithelium } \\
\hline Negative & 154 & 27 & 17 & 198 & 0.263 \\
\hline Positive & 40 & 11 & 2 & 53 & \\
\hline $1+$ & 36 & 7 & 2 & 45 & 0.067 \\
\hline $2+$ & 4 & 4 & $\boldsymbol{O}$ & 8 & \\
\hline Total & 194 & 38 & 19 & 251 & \\
\hline \multicolumn{6}{|l|}{ Stroma } \\
\hline Negative & 150 & 24 & 10 & 184 & $0.004^{*}$ \\
\hline Positive & 69 & 20 & 16 & 105 & \\
\hline $1+$ & 29 & 5 & 2 & 36 & \\
\hline $2+$ & 39 & 14 & 13 & 66 & $0.002^{*}$ \\
\hline $3+$ & 1 & 1 & 1 & 3 & \\
\hline Total & 219 & 44 & 26 & 289 & \\
\hline
\end{tabular}

*Indicates statistically significant values.

The bold values were used to indicate that these values reflected the intensity of staining in the positive categories, and the corresponding $P$-values in bold were for the correlation between staining intensity and the phyllodes tumor grade.

Table 4 Association of CD117 immunostaining with grade of phyllodes tumors

\begin{tabular}{|c|c|c|c|c|c|}
\hline CD117 immunohistochemistry & Benign no. & Borderline no. & Malignant no. & Total no. & $\mathrm{P}$-value \\
\hline \multicolumn{6}{|l|}{ Epithelium } \\
\hline Negative & 65 & 19 & 8 & 92 & 0.262 \\
\hline Positive & 139 & 24 & 12 & 175 & \\
\hline $1+$ & 39 & 10 & 3 & 52 & \\
\hline $2+$ & 82 & 12 & 8 & 102 & 0.826 \\
\hline $3+$ & 18 & 2 & 1 & 21 & \\
\hline Total & 204 & 43 & 20 & 267 & \\
\hline \multicolumn{6}{|l|}{ Stroma } \\
\hline Negative & 199 & 37 & 20 & 256 & $<0.001^{*}$ \\
\hline Positive & 7 & 4 & 6 & 17 & \\
\hline $1+$ & 1 & 1 & 2 & 4 & 0.001 * \\
\hline $2+$ & 6 & 3 & 4 & 13 & \\
\hline Total & 206 & 41 & 26 & 273 & \\
\hline
\end{tabular}

* Indicates statistically significant values.

See footnote in Table 3.

median 5\%) (Figure $1 \mathrm{~b}$ and c). Borderline and malignant phyllodes tumors were more likely to reveal stromal staining of moderate than weak intensity. Statistically significant correlations between p53 stromal immunostaining and morphologic parameters are depicted in Table 1. No correlation of stromal positivity with patient age, tumor size or margin status was observed. There was also no association between p53 immunoreactivity of either epithelium or myoepithelium with any histologic features. Stromal p53 positivity was correlated with luminal epithelial and myoepithelial p53 immunoexpression $(P<0.001)$.

\section{CD117}

For CD117, 267 and 273 microarrays could be assessed for epithelial and stromal staining characteristics (Figure 2a and b). No reactivity was observed in myoepithelial cells. Like for p53, there were microarrays in which epithelium was absent, thereby resulting in more cases disclosing results for CD117 immunostaining of stromal cells. Table 4 shows the distribution of CD117 immunohistochemical findings, including the staining intensities in histologically benign, borderline and malignant lesions. Unusually, CD117 stromal staining in 

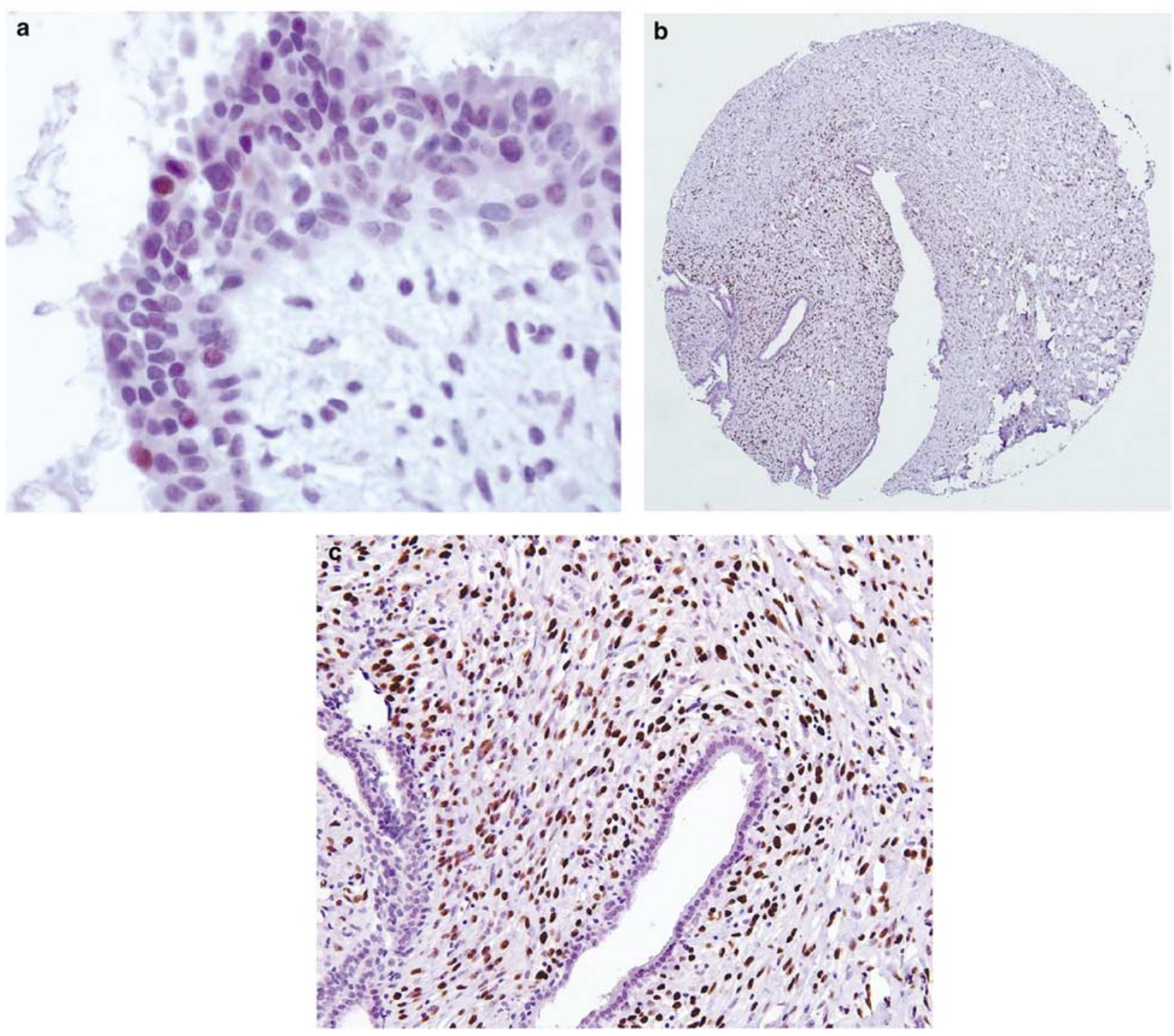

Figure 1 (a) p53 immunostaining of the epithelial component in a phyllodes tumor, showing focal and patchy nuclear positivity. (b) Stromal cells of a phyllodes tumor in a tissue microarray revealing strong nuclear staining. (c) Higher magnification of p53 immunostaining within stromal cells of a phyllodes tumor.

benign phyllodes tumors tended to be of moderate than weak intensity, when compared against borderline and malignant ones. Statistically significant correlations between CD117 stromal staining and morphologic parameters are depicted in Table 2 . There was no association of CD117 stromal staining with margin status, nor epithelial CD117 reactivity with histologic features.

\section{Recurrences}

A total of $43(13 \%)$ women suffered 57 recurrences during the follow-up period (mean and median follow-up duration of 30.3 and 20.4 months, respectively). The relationship between clinicopathologic parameters and onset of first local recurrence has been previously discussed. ${ }^{15}$ Of note, there was no statistically significant association of p53 immunostaining (epithelium, myoepithelium or stroma) with recurrent disease. On the other hand, CD117 stromal immunopositivity was correlated with recurrence $(P=0.001)$, with cases showing stromal reactivity for CD117 being more likely to recur than those that were negative (Table 5).

\section{Discussion}

Biological markers have often been used as adjuncts to morphology in predicting behavior of tumors. p53 is a tumor suppressor gene that is widely studied in neoplastic processes. Located on chromosome $17 \mathrm{p} 13.1$, it encodes for a $53 \mathrm{kDa}$ nuclear phospho- 

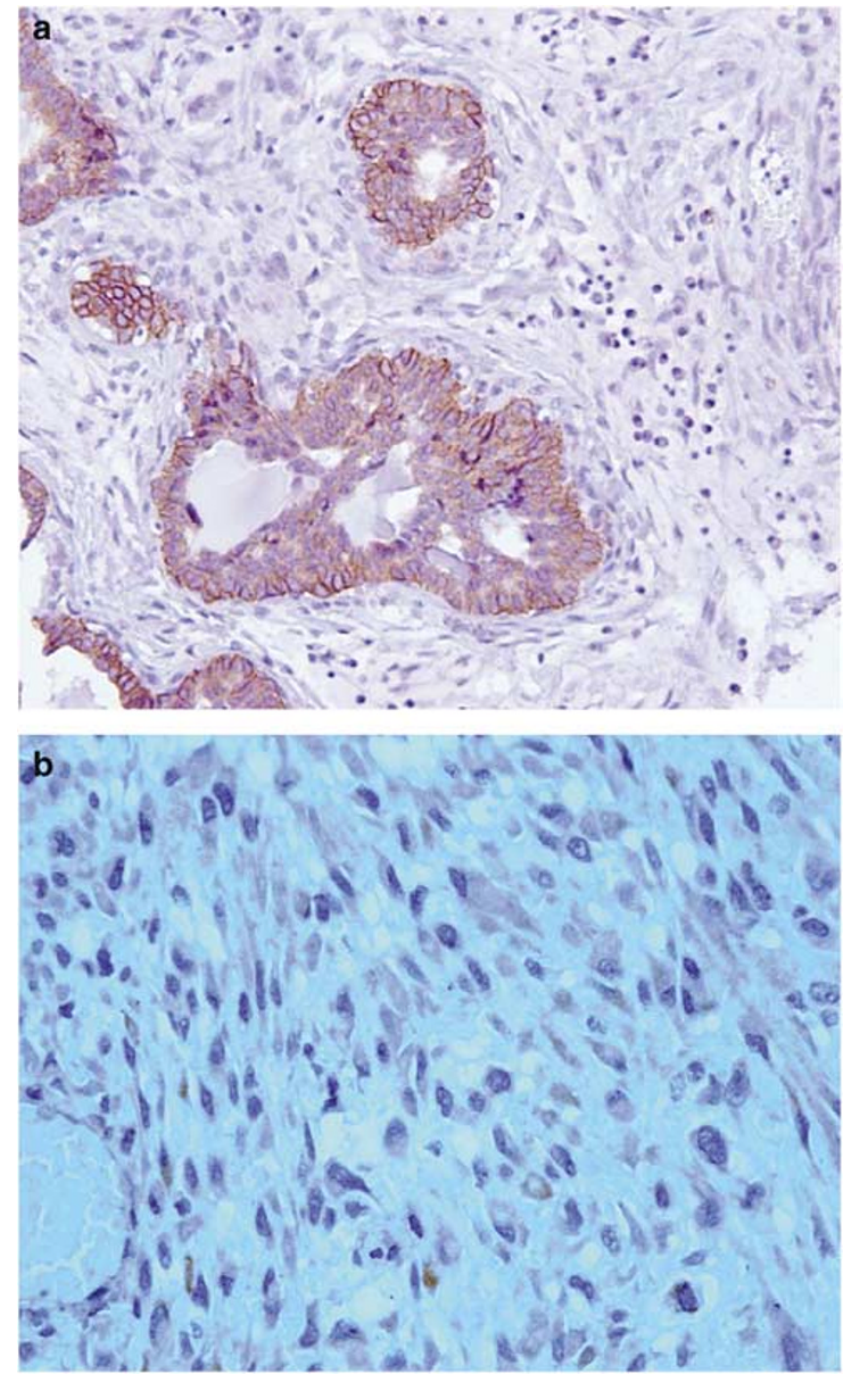

Figure 2 (a) CD117 decorates the epithelium of a phyllodes tumor, with cytoplasmic and cytoplasmic membrane staining. (b) CD117 cytoplasmic positivity in stromal cells of a phyllodes tumor.

Table 5 Correlation between CD117 stromal immunohistochemical staining and recurrence of phyllodes tumors

\begin{tabular}{lrrr}
\hline $\begin{array}{l}\text { CD117 stromal } \\
\text { immunohistochemical }\end{array}$ & No & Recurrence & Total \\
staining & recurrence & & \\
\hline Negative & & & \\
Positive & 232 & 24 & 256 \\
Total & 10 & 7 & 17 \\
\hline
\end{tabular}

protein that is expressed in all normal cells at low levels. ${ }^{23}$ The wild-type (normal) p53 gene is involved in cell cycle regulation as well as apoptosis. As the half-life of wild-type p53 is short, immunohistochemistry is believed to highlight expression of mutant p53 protein that is more stable with a longer half-life. In breast phyllodes tumors, the role of $p 53$ has been fairly well investigated, ${ }^{1,16-19}$ with some authors suggesting a possible prognostic function, ${ }^{16,18,19}$ while its predictive utility has not been validated by others. ${ }^{1,17}$ It is stated that p53 immunohistochemical expression in stromal cells can be relied upon as an adjunctive tool in the diagnosis of malignancy in phyllodes tumors. ${ }^{24,25}$ In our study, p53 staining was correlated with grade, with contributions from stromal hypercellularity and overgrowth, but did not reveal an association with recurrent disease, corroborating the conclusions of other authors, and supporting its potential use as a confirmatory marker of malignancy in these tumors.

Interestingly, p53 immunohistochemical positivity was also noted in a proportion of luminal epithelial and myoepithelial cells in our series. Studies of p53 expression in phyllodes tumors have focused primarily on stromal cells, ${ }^{14,16-18,25}$ with observation of perithelial accentuation of stromal cell staining. ${ }^{14,18}$ Feakins et $a l^{1}$ mentioned that the epithelial component in their cases usually stained negatively, while in another two reports, p53 reactivity was described in the breast epithelium in conjunction with stromal staining, ${ }^{26,27}$ and it was postulated that dual expression of p53 protein in both the epithelium and stroma reflected the existence of an interaction between these components, ${ }^{26}$ akin to the conclusion of Sawyer et al, ${ }^{28}$ who believed that both epithelium and stroma of phyllodes tumors were participants in the neoplastic process. Our finding of an association between p53 stromal staining with that in luminal and myoepithelium lends credence to this purported relationship, although the presence of myoepithelial staining and its possible role in this process is unclear.

CD117, also known as c-kit, is a membrane-bound tyrosine kinase receptor. Dimerization and autophosphorylation of CD117 is known to inhibit apoptosis via the phosphatidylinositol-3 kinase/Akt system and potentiate cell proliferation via the Ras/MAP kinase pathway and JAK/STA signalling. ${ }^{29}$ As CD117 overexpression is characteristically observed in gastrointestinal stromal tumors, ${ }^{30}$ it has served as a therapeutic target by drugs (Glivec) used to manage patients with these tumors. More recently, CD117 has also been found in the stromal cells of malignant phyllodes tumors, and it was postulated that its overexpression may be instrumental in the growth of these tumors. ${ }^{20}$ Although gain-of-function mutations of $C D 117$ have been reported in gastrointestinal stromal tumors, mast cell neoplasms and germ cell tumors, ${ }^{29}$ no activating mutations of CD117 have been described in breast phyllodes tumors. ${ }^{20,31}$

In our study, CD117 protein expression within stromal cells was significantly associated with myriad morphologic parameters, including grade and recurrent disease. It can be argued that the strength of these correlations is diminished by the 
fact that only 17 cases were CD117 stromal positive on immunohistochemistry in our series. Nevertheless, its association with grade has been corroborated by other authors. ${ }^{20,21}$ There was also a correlation of CD117 with p53 stromal staining, which suggests the possibility of these two proteins cooperating in potentiating cell cycle progression. After all, mutant forms of the p53 protein are known to interfere with cell growth suppressor effects of wild-type p53 and $C D 117$ is associated with cell growth. If the role of $C D 117$ in malignancy and recurrence of phyllodes tumors is validated, its expression can be advantageously harnessed for therapeutic purposes.

While studies on p53 and c-kit have predominantly dealt with protein expression using immunohistochemistry, it will be useful to validate these findings at the molecular level in order to determine specific genetic abnormalities in the responsible genes. Sequencing of the p53 gene carried out by various authors has discovered mostly mutations, ${ }^{16,24}$ although one study disclosed a wild-type gene sequence in a malignant phyllodes tumor. ${ }^{32}$ Proliferative activity using Mib-1 and S-phase fraction, ${ }^{19,27}$ microvessel density, ${ }^{25}$ CD34 and factor XIIIa stromal positivity ${ }^{33}$ are also believed to be potentially helpful in predicting phyllodes tumor behavior, although their clinical relevance remains to be further ratified.

The use of tissue microarrays has revolutionized translational research by allowing the rapid screening of numerous tumor samples simultaneously to validate candidate genes as potential prognostic markers. ${ }^{22}$ In this study, tissue microarray technology was used to evaluate the immunohistochemical expression of p53 and CD117 in a large series of breast phyllodes tumors. If standard histological sections were used, the number of sections requiring assessment would be much greater, incurring not only substantially more time, but also additional cost of antibodies and reagents because of the larger sections and greater number of slides. Previous reports reviewing the accuracy and reliability of tissue microarray vs standard sections on breast cancers have concluded that results derived from tissue microarrays are representative. ${ }^{34,35}$ In this current study, when cases constructed in duplicate, triplicate and more microarray cores were compared, 85 and $92 \%$ of cases revealed agreement of p53 and CD117 immunohistochemical findings, respectively, when positive vs negative immunostaining of stromal cells was evaluated. We compared only stromal immunostaining as this was the cellular component under main scrutiny in these tumors. The lesser degree of immunostaining concordance for stromal p53 may be attributable to tumor heterogeneity, possibly linked to tumor size, suggesting that for phyllodes tumors that achieve relatively large dimensions, a recommendation to increase the number of punches/arrays commensurate with the lesional size may be warranted. The fact that p53 stromal staining displayed less concordance among the duplicate/triplicate/more cores than CD117 may also indicate that p53 immunoexpression tends to be more patchy and variable in phyllodes tumor stroma. An additional advantage of utilizing the tissue microarray method of evaluating this series of phyllodes tumors for p53 and CD117 protein expression is that it will allow expeditious selection of cases for further molecular studies.

In conclusion, p53 and CD117 protein expression by stromal cells in phyllodes tumors is correlated with histologic parameters such as grade, implying a possible role of their being used as adjunctive markers of malignancy in these tumors. The association of p53 immunostaining of the epithelium, myoepithelium and stroma affirms a link between these cellular compartments, a relationship that awaits further clarification. Although the number of CD117 stroma-positive cases is small, its expression appears to be associated with recurrent likelihood, and this needs to be investigated. The tissue microarray technique can be effectively applied to large numbers of phyllodes tumors to study other biological markers that may be of potential predictive utility.

\section{Acknowledgements}

We thank the Singapore Cancer Registry, National Disease Registries Office, for follow-up information. Parts of this study were presented at the 94th Annual Meeting of the United States and Canadian Academy of Pathology, San Antonio, Texas, USA, 2005. This study was supported by grants from the Department of Clinical Research, Singapore General Hospital, and the Singapore Cancer Syndicate (MS0004).

\section{References}

1 Feakins RM, Mulcahy HE, Nickols CD, et al. p53 expression in phyllodes tumors is associated with histological features of malignancy but does not predict outcome. Histopathology 1999;35:162-169.

2 Keelan PA, Myers JL, Wold LE, et al. Phyllodes tumor: clinicopathologic review of 60 patients and flow cytometric analysis in 30 patients. Hum Pathol 1992; 23:1048-1054.

3 Kuijper A, Buerger H, Simon R, et al. Analysis of the progression of fibroepithelial tumors of the breast by PCR-based clonality assay. J Pathol 2002;197:575-581.

4 Noguchi S, Yokouchi H, Aihara T, et al. Progression of fibroadenoma to PT demonstrated by clonal analysis. Cancer 1995;76:1779-1785.

5 Zurrida S, Bartoli C, Galimberti V, et al. Which therapy for unexpected phyllode tumor of the breast. Eur J Cancer 1992;28:654-657.

6 Moffat CJC, Pinder SE, Dixon AR, et al. Phyllodes tumors of the breast: a clinicopathological review of thirty-two cases. Histopathology 1995;27:205-218. 
7 Reinfuss M, Mitus J, Smolak K, et al. Malignant phyllodes tumors of the breast. A clinical and pathological analysis of 55 cases. Eur J Cancer 1993; 29A:1252-1256.

8 Reinfuss M, Mitus J, Duda K, et al. The treatment and prognosis of patients with phyllodes tumor of the breast. An analysis of 170 cases. Cancer 1996;77: 910-916.

9 Chaney AW, Pollack A, Mcneese MD, et al. Primary treatment of cystosarcoma phyllodes of the breast. Cancer 2000;89:1502-1511.

10 Hawkins RE, Schofield JB, Fisher C, et al. The clinical and histologic criteria that predict metastases from cystosarcoma phyllodes. Cancer 1992;69: 141-147.

11 Cohn-Cedermark G, Rutqvist LE, Rosendahl I, et al. Prognostic factors in cystosarcoma phyllodes. A clinicopathologic study of 77 patients. Cancer 1991; 68:2017-2022.

12 Pietruszka M, Barnes L. Cystosarcoma phyllodes. A clinicopathologic analysis of 42 cases. Cancer 1978; 41:1974-1983.

13 Barth Jr RJ. Histologic features predict local recurrence after breast conserving therapy of PT. Breast Cancer Res Treat 1999;57:291-295.

14 Kleer CG, Giordano TJ, Braun T, et al. Pathologic, immunohistochemical, and molecular features of benign and malignant PT of the breast. Mod Pathol 2001;14:185-190.

15 Tan PH, Jayabaskar T, Chuah KL, et al. Phyllodes tumors of the breast. The role of pathologic parameters. Am J Clin Pathol 2005;123:529-540.

16 Kuenen-Boumeester V, Henzen-Logmans SC, Timmermans MM, et al. Altered expression of p53 and its regulated proteins in phyllodes tumors of the breast. J Pathol 1999;189:169-175.

17 Tse GMK, Putti TC, Kung FYL, et al. Increased p53 protein expression in malignant mammary phyllodes tumors. Mod Pathol 2002;15:734-740.

18 Millar EKA, Beretov J, Marr P, et al. Malignant phyllodes tumors of the breast display increased stromal p53 protein expression. Histopathology 1999; 34:491-496.

19 Niezabitowski A, Lackowska B, Rys J, et al. Prognostic evaluation of proliferative activity and DNA content in the PT of the breast: immunohistochemical and flow cytometric study of 118 cases. Breast Cancer Res Treat 2001;65:77-85.

20 Sawyer EJ, Poulsom R, Hunt FT, et al. Malignant phyllodes tumors show stromal overexpression of c-myc and c-kit. J Pathol 2003;200:59-64.
21 Chen CM, Chen CJ, Chang CL, et al. CD34, CD117, and actin expression in phyllodes tumor of the breast. J Surg Res 2000;94:84-91.

22 Tan Y, Hilmy MH, Hung $\mathrm{H}$, et al. Initial experience with tissue microarray (TMA) in a surgical pathology laboratory: technical considerations. The J Histotechnol 2004;27:113-117.

23 Tan PH, Ho GH, Ji CY, et al. Immunohistochemical expression of p53 protein in invasive breast carcinoma: clinicopathologic correlations. Oncol Rep 1999; 6:1159-1163.

24 Gatalica Z, Finkelstein S, Lucio E, et al. p53 protein expression and gene mutation in phyllodes tumors of the breast. Pathol Res Pract 2001;197:183-187.

25 Tse GM, Lui PC, Scolyer RA, et al. Tumor angiogenesis and p53 protein expression in mammary phyllodes tumors. Mod Pathol 2003;16:1007-1013.

26 Dacic S, Kounelis S, Kouri E, et al. Immunohistochemical profile of cystosarcoma phyllodes of the breast: a study of 23 cases. Breast J 2002;8:376-381.

27 Witte F, Honig A, Mirecka J, et al. Cystosarcoma phyllodes of the breast: prognostic significance of proliferation and apoptosis associated genes. Anticancer Res 1999;9:3355-3360.

28 Sawyer EJ, Hanby AM, Ellis P, et al. Molecular analysis of phyllodes tumors reveals distinct changes in the epithelial and stromal components. Am J Pathol 2000; 156:1093-1098.

29 Kitamura Y, Hirotab S. Kit as a human oncogenic tyrosine kinase. Cell Mol Life Sci 2004;61:2924-2931.

30 Hornick JL, Fletcher CD. Validating immunohistochemical staining for KIT (CD117). Am J Clin Pathol 2003;119:325-327.

31 Carvalho S, e Silva AO, Milanezi F, et al. c-KIT and PDGFRA in breast phyllodes tumours: overexpression without mutations? J Clin Pathol 2004;57:1075-1079.

32 Woolley PV, Gollin SM, Riskalla W, et al. Cytogenetics, immunostaining for fibroblast growth factors, p53 sequencing, and clinical features of two cases of cystosarcoma phyllodes. Mol Diagn 2000;5:179-190.

33 Silverman JS, Tamsen A. Mammary fibroadenoma and some phyllodes tumor stroma are composed of CD34+ fibroblasts and factor XIIIa+ dendrophages. Histopathology 1996;29:411-419.

34 Zhang D, Salto-Tellez M, Putti TC, et al. Reliability of tissue microarrays in detecting protein expression and gene amplification in breast cancer. Mod Pathol 2003;16:79-84.

35 Shergill IS, Shergill NK, Arya M, et al. Tissue microarrays: a current medical research tool. Curr Med Res Opin 2004;20:707-712. 